\title{
Aproveitamento dos resíduos de priprioca (Cyperus articulatus L.) no controle alternativo de fungos fitopatogênicos
}

Fungos fitopatogênicos são responsáveis por doenças que causam grandes perdas agrícolas. O tratamento convencional é realizado por agrotóxicos e embora esses produtos reduzam significativamente as perdas, ocasionam sérias contaminações ambientais, contribuem para o surgimento de patógenos resistentes e eliminam agentes de controle biológico natural. Produtos naturais obtidos de plantas, como óleos essenciais e extratos, possuem substâncias bioativas que têm demonstrado potencial atividade antifúngica. A priprioca (Cyperus articulatus L.) é uma planta encontrada na Amazônia, muito utilizada no preparo de colônias artesanais. A alguns anos, o óleo essencial da espécie se tornou matéria-prima da Perfumaria Nacional e seu cultivo passou a ser em escala comercial, tornando-se fonte de renda para comunidades do entorno de Belém/PA. No processo de obtenção de óleo essencial são gerados grandes quantidades de resíduo sólido (massa vegetal após a retirada do óleo essencial). Esse trabalho teve como objetivo a avaliação e comparação da atividade antifúngica do óleo essencial, extrato hexânico e etanólico de priprioca e extrato hexânico e etanólico do resíduo sólido de priprioca, visando o aproveitamento dos resíduos no controle de fitopatógenos responsáveis por grandes perdas na produção agrícola. Para tanto, óleo essencial foi extraído por hidrodestilação (6h) e os extratos obtidos via Soxhlet (8h). Foram avaliadas as Concentrações Mínimas Inibitória (CMI) pelo método de microdiluição e a Concentração Fungicida Mínima (CFM) para os tratamentos ativos. Foram avaliadas as concentrações de $1000 \mathrm{aa} 15,625 \mu \mathrm{g} / \mathrm{mL}$ frente a Fusarium oxysporum, Sclerotinia sclerotiorum e Macrophomina phaseolina. Os extratos etanólicos e hexânico do resíduo sólido apresentaram maior atividade antifúngica, principalmente frente a S. sclerotiorum, sendo fungicidas a 125 e $250 \mathrm{\mu g} / \mathrm{mL}$, respectivamente. O óleo essencial foi inativo frente aos fitopatógenos teste. Tais resultados indicaram a eficácia dos extratos do resídu de priprioca frente a fungos fitopatogênicos. O resíduo sólido é gerado em grandes quantidades durante a extração do óleo essencial e não possui valor agregado, tornando-o candidato a matéria-prima de produtos sustentáveis e de baixo impacto ambiental, que atuem no controle alternativo de fungos fitopatogênicos.

Palavras-chave: Atividade antifúngica; Fitopatógenos; Óleo essencial; Extratos.

\section{Utilization of priprioca (Cyperus articulatus L.) residues in alternative control of phytopathogenic fungi}

\begin{abstract}
Plant pathogenic fungi are responsible for diseases that cause large agricultural losses. Conventional treatment is carried out by pesticides and although these products significantly reduce losses, plants, such as essential oils and extracts, have bioactive substances that have demonstrated potential antifungal activity. Priprioca (Cyperus articulatus L.) is a plant found in the Amazon, plants, such as essential oils and extracts, have bioactive substances that have demonstrated potential antifungal activity. Priprioca (Cyperus articulatus L.) is a plant found in the Amazon, widely used in the preparation of artisanal colonies. A few years ago, the essential oil of the species became raw material of the National Perfumery and its cultivation became commercial
scale, becoming a source of income for communities around Belém/PA. In the process of obtaining essential oil, large quantities of solid waste are generated (vegetable mass after removal of the essential oil). The objective of this work was to evaluate and compare the antifungal activity of priprioca essential oil, hexane and ethanolic extract and hexane and ethanolic extract of priprioca solid waste, aiming at the use of residues in the control of phytopathogens. For this, essential oil was extracted by hydrodistillation (6h) and extracts obtained via Soxhlet (8h). Minimum Inhibitory Concentrations (MIC) were evaluated by the microdilution method and Minimum Fungicidal Concentration (CFM) for the active treatments. Concentrations of 1000 to $15.625 \mu \mathrm{g} / \mathrm{mL}$ against Fusarium oxysporum, Sclerotinia sclerotiorum and Macrophomina phaseolina were evaluated. The ethanolic and hexane extracts of the solid residue showed higher antifungal activity, especially against S. sclerotiorum, being fungicides at 125 and $250 \mu \mathrm{g} / \mathrm{mL}$, respectively. The essential oil was inactive against the phytopathogens test. These results indicated the effectiveness of extracts of $p$ of essential oil and has no added value, making it a candidate for raw materials of sustainable and low environmental impact products that act in the alternative control of phytopathogenic fungi.
\end{abstract}

Keywords: Antifungal activity; Phytopathogens; Essential oil; Extracts.

Aline Aparecida Munchen Kasper (iD) Universidade Federal do Oeste do Pará, Brasil http://lattes.cnpq.br/8775156657725568 http://orcid.org/0000-0003-2613-5125 aliny_@msn.com

Sara Freitas de Sousa

Universidade Federal do Oeste do Pará, Brasil http://lattes.cnpq.br/0444579834038751 http://orcid.org/0000-0002-1305-8514 sara freitas stm@hotmail.com

Breno Sena de San Martin (iD

Universidade Federal do Oeste do Pará, Brasil http://lattes.cnpq.br/9486020248465637

http://orcid.org/0000-0002-7349-3446

brenosanmartin95@gmail.com

\section{Adilson Sartoratto (iD) \\ Universidade Estadual de Campinas, Brasil http://lattes.cnpq.br/2938768700584296 http://orcid.org/0000-0002-1763-3715 adilson@cpqba.unicamp.br}

Kariane Mendes Nunes

Universidade Federal do Oeste do Pará, Brasi http://lattes.cnpq.br/9309973943729721 http://orcid.org/0000-0003-2178-0336 kariane.nunes@gmail.com

José Jeosafa Vieira de Sousa Júnior (iD Universidade Federal do Oeste do Pará, Brasil http://lattes.cnpq.br/2162716940839053 http://orcid.org/0000-0001-8790-0711 josejeosatajrstm@hotmail.com
Silvia Katrine Rabelo da Silva (D) Universidade Federal do Oeste do Pará, Brasil http://lattes.cnpq.br/6999618172919722 http://orcid.org/0000-0002-9408-131X katrinerabelos@gmail.com

Lauro Euclides Soares Barata (DD Universidade Federal do Oeste do Pará, Brasil http://lattes.cnpq.br/1609747051706094 http://orcid.org/0000-0003-0909-769X lauroesbarata@gmail.com Aproveitamento dos resíduos de priprioca (Cyperus articulatus L.) no controle alternativo de fungos fitopatogênicos. Revista lbero Americana de Ciências Ambientais, v.11, n.1, p.80-88, 2020. DOI: http://doi.org/10.6008/CBPC2179-6858.2020.001.0009 


\section{INTRODUÇÃO}

As doenças fúngicas são responsáveis por perdas significativas na produção agrícola. A demanda crescente de alimentos traz a necessidade de controle dessas doenças, atualmente realizado com tratamento convencional utilizando agrotóxicos. Embora esses produtos contribuam de maneira significativa para reduções nas perdas agrícolas, o uso indiscriminado e ininterrupto desses agrotóxicos tem levado a contaminações ambientais, surgimento de patógenos resistentes e eliminação de agentes do controle biológico natural (SOYLU et al., 2010).

A utilização de produtos naturais como agentes de controle alternativo de fungos fitopatogênicos tem sido amplamente estudada nos últimos anos. Os produtos naturais, como extratos e óleos essenciais contém metabólitos secundários que tem demonstrado atividade potencial no manejo de doenças de plantas (SILVA et al., 2010). Além das propriedades antimicrobianas, os produtos naturais são biodegradáveis, ocasionando menos danos ao meio ambiente (OOTANI et al., 2011).

A Amazônia possui um grande acervo de produtos naturais, com potencial aplicação biotecnológica, como, por exemplo, a priprioca. A priprioca (Cyperus articulatus L.) é um recurso aromático do Pará, já cultivada em escala comercial nas regiões do entorno de Belém para a extração do óleo essencial, utilizado como matéria-prima pela empresa Natura $^{\circledR}$. O resíduo sólido (material vegetal após a extração do óleo essencial) entretanto, é descartado. A utilização desse subproduto vem de encontro as premissas da agroecologia, que visa utilizar matérias-primas naturais e sustentáveis para controle alternativo de doenças fúngicas, diminuindo assim impactos da produção agrícola.

Nesse contexto, o objetivo desse trabalho foi avaliar e comparar a atividade antifúngica do óleo essencial e do extratos de rizomas e tubérculos de priprioca e de extratos do resíduo sólido de priprioca frente a Fusarium oxysporum, Sclerotinia sclerotiorum e Macrophomina phaseolina, visando promover estratégias de aproveitamento dos resíduos no controle alternativo de fitopatógenos causadores de grandes perdas agrícolas.

\section{REVISÃO TEÓRICA}

Fungicidas comerciais têm sido amplamente utilizados para evitar perdas agrícolas causadas por fungos fitopatogênicos. Entretanto, os danos dos resíduos desses agroquímicos no ambiente e o desenvolvimento de resistência dos patógenos tem induzido a pesquisa de métodos de controle alternativo (CELOTO et al., 2011). Nessa busca as plantas tem sido destaque, devido aos de metabólitos secundários presentes em sua composição, muitas vezes com potencial fungicida ou fungistático. Esses metabólitos secundários são fundamentais a sobrevivência dos organismos que os produzem. A diversidade estrutural desses compostos faz com que sejam de grande interesse para a espécie humana, sendo utilizados na pesquisa e desenvolvimento de fármacos, produtos alimentícios, cosméticos e agroquímicos (CELOTO et al., 2008).

A priprioca, uma espécie encontrada nas regiões norte e nordeste do Brasil, apresenta-se como uma 
planta perene com rizoma endurecido, tendo seus tubérculos cobertos com brácteas avermelhadas, multinérveas e lanceoladas, com escapo cilíndrico a trígono e liso. Os órgãos aéreos da planta são escapos e folhas, enquanto órgãos subterrâneos são rizomas, tubérculos e raízes. A altura da planta varia de 30 a 250 $\mathrm{cm}$. As células oleíferas são encontradas exclusivamente nos rizomas e tubérculos, como é característico na família Cyperaceae, são de paredes delgadas e distribuição aleatória, mas encontram-se em maior porcentagem nos tubérculos do que nos rizomas.

Em países da África e na Amazônia, rizomas e tubérculos de priprioca são muito utilizados na medicina tradicional para o tratamento de diversas enfermidades como enxaqueca, dor de estômago, febre, malária, também possuindo propriedades contraceptivas e abortivas (NGO BUM et al., 2001). Inúmeras atividades biológicas já foram constatadas para C. articulatus, dentre elas: anticonvulsivante (NGO BUM et al., 2001), antiplasmódica (RUKUNGA et al., 2008), antiespasmódica (SOUSA et al., 2008), alelopática (SOUZA FILHO et al., 2008), antioncocercose (METUGE et al., 2014), efeito hepatoprotetor (DATTA et al., 2013), sedativa (RAKOTONIRINA et al., 2001), repelente (ABUBAKAR et al., 2000).

A atividade antimicrobiana da espécie também já foi relatada por alguns autores. Alguns autores relataram a atividade antibacteriana do óleo essencial de $C$. articulatus oriundas da Nigéria e apontam para a maior susceptibilidade de bactérias do tipo gram-negativo a esse óleo essencial. Em estudo foi relatado a decocção de rizomas de $C$. articulatus coletados na área do rio Tambopata, em Madre de Dios, Peru, durante o mês de Janeiro de 1994. Testes antimicrobianos revelaram que Staphylococcus aureus foi totalmente inibida pela decocção de $C$. articulatus, no entanto não apresentaram efeito inibitório contra Escherichia coli, Salmonella gallinarum, Klebsiella pneumoniae e Cândida albicans. A atividade anti-cândida de plantas brasileiras foi constatada nos estudos de Duarte et al. (2005) sendo uma destas plantas a priprioca. Foram testados o óleo essencial e o extrato etanólico da espécie. O óleo essencial foi considerado moderadamente inibitório, enquanto que o extrato etanólico foi considerado fracamente inibitório. Os autores concluíram que para se atingir a concentração mínima inibitória seriam necessárias altas concentrações do óleo essencial e do extrato

No estado do Pará, a priprioca também é usada em banhos de cheiro em festas de São João e na aromatização da água de lavagem devido a sua fragrância agradável, o aroma, conhecido como cheiro do Pará, foi introduzido há muitos anos nos perfumes regionais. $O$ óleo essencial da espécie possui coloração amarelo forte e aroma amadeirado, fresco e picante, sendo difícil reproduzi-lo sinteticamente (NICOLLI et al., 2006). Atualmente, o óleo essencial é matéria-prima para a produção do perfume que leva o nome 'Rara Priprioca' pela empresa, agora multinacional, Natura ${ }^{\circledR}$.

A obtenção do óleo essencial gera como subproduto o resíduo sólido (massa vegetal após processo de extração de óleo essencial). Assim como a maioria das plantas, a priprioca apresenta baixo rendimento de óleo essencial, o que exige grande quantidade de material vegetal, ocasionando a produção de grande volume de resíduo vegetal. Esse resíduo, ainda é descartado, embora comprovada a presença de substâncias bioativas nesse subproduto (KASPER et al. 2018a; KASPER et al., 2018b). 


\section{MATERIAIS E MÉTODOS}

\section{Coleta de material vegetal}

Os tubérculos, rizomas e raízes de priprioca ( $C$. articulatus) foram coletados no período chuvoso amazônico, na Fazenda Experimental da Universidade Federal do Oeste do Pará - UFOPA, localizada às margens da Rodovia Santarém-Curuá Una (PA-370), km 37, no município de Santarém. Para a coleta se utilizou enxadas para desenterrar os órgãos vegetativos subterrâneos, descartando-se a parte aérea.

\section{Obtenção dos produtos naturais de priprioca}

\section{Extração do óleo essencial}

Antes da extração, o material vegetal (rizomas, tubérculos e raízes) foi lavado em água corrente e seco em estufa a $35^{\circ} \mathrm{C}$ por $72 \mathrm{~h}$, triturado em moinho de facas e $600 \mathrm{~g}$ de material vegetal foi extraído em duplicata em aparelho de Clevenger, por hidrodestilação durante 6h. O líquido sobrenadante (óleo essencial) foi coletado e acondicionado em frascos âmbar estéril, mantidos sob refrigeração a $10^{\circ} \mathrm{C}$. O resíduo sólido foi seco em temperatura ambiente.

\section{Obtenção dos extratos de priprioca}

$100 \mathrm{~g}$ de rizomas, tubérculos e raízes triturados foram extraídos em duplicata em Soxhlet por 8h com etanol e com hexano, os extratos obtidos foram concentrados em evaporador rotativo a pressão reduzida a temperatura $50^{\circ} \mathrm{C}$. Após completa evaporação dos solventes, os extratos foram acondicionados em frascos âmbar estéreis mantidos sob refrigeração a $10^{\circ} \mathrm{C}$. Os rendimentos das extrações foram calculados em função da massa de produto obtido em razão da massa vegetal extraída multiplicada por 100 (TAUBE JR et al., 2014).

\section{Obtenção dos extratos do resíduo sólido de priprioca}

$100 \mathrm{~g}$ do resíduo sólido obtido no processo de hidrodestilação também foram submetidos a extração em duplicata de metabólitos remanescentes com hexano e etanol em equipamento de Soxhlet por $8 \mathrm{~h}$. Os extratos foram concentrados em evaporador rotativo a pressão reduzida e temperatura aproximada $50^{\circ} \mathrm{C}$. Após eliminação dos solventes, os extratos do resíduo sólido foram armazenados em frascos âmbar estéreis e mantidos sob refrigeração a $10^{\circ} \mathrm{C}$. Os rendimentos das extrações foram calculados em função da massa de produto obtido em razão da massa vegetal extraída multiplicada por 100 (TAUBE JR et al., 2014).

\section{Microrganismos utilizados}

Os fungos foram obtidos do acervo do Laboratório de Microbiologia, da Universidade Federal do Oeste do Pará - UFOPA. A atividade antifúngica foi avaliada frente aos microrganismos Fusarium oxysporum, Sclerotinia slerotiorum e Macrophomina phaseolina, fitopatógenos responsáveis por infecções diferentes em cultivos de plantas. 


\section{Concentração Mínima Inibitória (CMI) e Concentração Mínima Fungicida (CMF)}

Para a avaliação da concentração mínima inibitória (CMI) foram utilizadas microplacas estéreis de 96 poços utilizando o meio Batata-Dextrose (BD) com 5\% de dimetilsulfóxido (DMSO). As suspensões fúngicas foram ajustadas na escala 0,5 MacFarland com caldo BD estéril a 0,9\% em espectrofotômetro, à densidade ótica de 0,284 e comprimento de onda a $530 \mathrm{~nm}$, equivalente a $10^{4}$ esporos $/ \mathrm{mL}$. Os tratamentos foram avaliados em triplicata, sendo que para o óleo essencial foram depositados $100 \mu \mathrm{L}$ na primeira linha e $100 \mu \mathrm{L}$ de óleo essencial juntamente com $100 \mu \mathrm{L}$ de meio na segunda linha, sendo a microdiluição iniciada na segunda linha. Nos demais poços foram depositados $100 \mu \mathrm{L}$ de meio. Para os extratos foram depositados 100 $\mu \mathrm{L}$ de solução mãe a $2000 \mu \mathrm{g} / \mathrm{mL}$ juntamente com $100 \mu \mathrm{L}$ de meio de cada tratamento sendo a microdiluição iniciada na primeira linha. Para a microdiluição o conteúdo dos orifícios da primeira linha (para extratos) e da segunda linha (para óleo essencial) foram homogeneizados com o meio e transferidos para os orifícios da linha seguinte, repetindo-se o processo até a penúltima linha, sendo os $100 \mu \mathrm{L}$ final desprezados. As concentrações avaliadas foram 1000 a 15,625 $\mu \mathrm{g} / \mathrm{mL}$. Nas linhas com a microdiluição foram adicionados 10 $\mu \mathrm{L}$ do inóculo padronizado, selando as placas com plástico. Na última linha da placa de microdiluição foi realizado o controle de esterilidade do meio, o controle positivo com o antifúngico comercial Azimut ${ }^{\circledR}$ e a avaliação da viabilidade dos patógenos. As placas foram incubadas em estufa a $32^{\circ} \mathrm{C}$ por $96 \mathrm{~h}$. Após o período de incubação foram adicionados $50 \mu \mathrm{L}$ de solução $0,1 \%$ de resazurina para revelação, sendo placas reincubadas por $2 \mathrm{~h}$. A CMI foi definida como a menor concentração da amostra capaz de impedir o crescimento fúngico, por meio da observação da coloração azulada conferida ao meio pelo revelador químico resazurina. Quando as células apresentam atividade respiratória após a revelação ocorre uma reação de oxirredução, na qual a resazurina é convertida a resorufina, característica por sua coloração rosada.

Para determinar a Concentração Fungicida Mínima (CFM), todos os poços do ensaio anterior (CMI) que permanecerem com coloração azulada, característica da resazurina, tiveram $10 \mu \mathrm{L}$ transferidos das repetições para placas de petri contendo meio BDA (Batata-Dextrose-Ágar). As placas foram reincubadas em estufa a $32^{\circ} \mathrm{C}$ por $96 \mathrm{~h}$. Após o tempo de incubação a verificação da ausência de crescimento fúngico nas placas revela a menor concentração necessária de óleo ou extrato necessária para que a amostra apresente atividade fungicida.

\section{RESULTADOS}

\section{Rendimentos e identificação das classes de metabólitos secundários presentes}

Na tabela 1 estão descritos os rendimentos obtidos para os produtos naturais extraídos de $C$. articulatus. A caracterização das classes de metabólitos secundários realizada por meio de Cromatografia em Camada Delgada (CCD) identificou a presença de terpenos no óleo essencial, e de terpenos, flavonoides, triterpenos, esteroides e ácidos graxos nos extratos íntegros e do resíduo de priprioca. 
Tabela 1: Rendimentos médios (\%) obtidos para o óleo essencial, extratos etanólico e hexânico de priprioca e etanólico e hexânico do resíduo sólido de priprioca (Cyperus articulatus L.).

\begin{tabular}{|l|l|}
\hline & Rendimento (\%) \\
\hline Óleo Essencial & 0,45 \\
\hline Extrato etanólico & 14,1 \\
\hline Extrato etanólico do resíduo sólido & 7,83 \\
\hline Extrato hexânico & 1,61 \\
\hline Extrato hexânico do resíduo sólido & 1,31 \\
\hline
\end{tabular}

\section{Atividade antifúngica}

Na tabela 2 estão descritas as concentrações mínimas necessárias para inibir o crescimento fúngico (CMI), expressas em $\mu \mathrm{g} / \mathrm{mL}$, para os produtos naturais obtidos de priprioca, para os fitopatógenos teste.

Tabela 2: Concentração Mínima Inibitória (CMI) em $\mu \mathrm{g} / \mathrm{mL}$ do óleo essencial, extrato etnólico e hexânico de priprioca e extrato etanólico e hexânico do resíduo sólido de priprioca (Cyperus articulatus L.) frente aos fungos fitopatogênicos Fusarium oxysporum, Sclerotinia sclerotiorum e Macrophomina phaseolina.

\begin{tabular}{|l|l|l|l|}
\hline $\mathrm{CMI}(\mu \mathrm{g} / \mathrm{mL})$ & Fusarium oxysporum & Sclerotinia sclerotiorum & Macrophomina phaseolina \\
\hline & $*$ & $*$ & $*$ \\
\hline Óleo essencial & 250 & $*$ & $*$ \\
\hline Extrato etanólico & 125 & 62,5 & $*$ \\
\hline Extrato etanólico do resíduo sólido & 125 & 62,5 & $*$ \\
\hline Extrato hexânico & 125 & 62,5 & \\
\hline Extrato hexânico do resíduo sólido & & $*$ \\
\hline
\end{tabular}

\section{* - $\mathrm{CMI}>1000 \mu \mathrm{g} / \mathrm{mL}$}

Na tabela 3 estão descritas as concentrações mínimas necessárias para obter efeito fungicida. Quando há crescimento fúngico após a semeadura em placas de Petri contendo meio BDA, o tratamento é considerado fungistático, ou seja, apenas inibe o crescimento do fitopatógeno.

Tabela 3: Concentração Mínima Fungicida (CMF) em $\mu \mathrm{g} / \mathrm{mL}$ do óleo essencial, extrato etanólico e hexânico de priprioca e extrato etanólico e hexânico do resíduo sólido de priprioca (Cyperus articulatus L.) frente aos fungos fitopatogênicos Fusarium oxysporum, Sclerotinia sclerotiorum e Macrophomina phaseolina.

\begin{tabular}{|l|l|l|l|}
\hline $\mathrm{CMF}(\boldsymbol{\mu g} / \mathrm{mL})$ & Fusarium oxysporum & Sclerotinia sclerotiorum & Macrophomina phaseolina \\
\hline & - & - & - \\
\hline Óleo essencial & - & - & - \\
\hline Extrato etanólico íntegro & 1000 & 125 & - \\
\hline Extrato etanólico do resíduo sólido & 250 & 250 & - \\
\hline Extrato hexânico íntegro & 250 & 250 & - \\
\hline Extrato hexânico do resíduo sólido & 250 & & - \\
\hline
\end{tabular}

\section{DISCUSSÃO}

O óleo essencial de priprioca apresenta um baixo rendimento $(0,45 \%)$, deste modo, é necessário um volume grande de material vegetal para obter óleo essencial, gerando o resíduo sólido, que geralmente é descartado. Anteriormente foram constatadas a presença de substâncias bioativas nos extratos do resíduo sólido (KASPER et al., 2018a; KASPER et al., 2018b; KASPER et al., 2018c).

Em estudos anteriores Kasper et al. (2018c) caracterizaram quimicamente os compostos majoritários do óleo essencial de priprioca extraído em Clevenger e por meio de Cromatografia Gasosa acoplada a Espectrometria de Massas identificando o $\alpha$-pineno, trans-pinocarveol, mirtenol, verbenona, $\alpha$-copaeno, $\beta$ selineno, óxido de cariofileno, aristolona, mustacona, 7-isopropenil-1,4a-dimetil-4,4a,5,6,7,8-hexahidro-3Hnaftalen-2-ona. 
A atividade antifúngica de óleos essenciais tem sido relatada por inúmeros autores (DINIZ et al., 2008; LEE et al., 2008; DAN et al., 2009; ABDOLAHI et al., 2010; PANSERA et al., 2012; HILLEN et al., 2012) entretanto o óleo essencial de priprioca foi inativo nas concentrações avaliadas frente aos fitopatógenos teste. Duarte et al. (2005) relataram ausência de atividade inibitória do óleo essencial de C. articulatus frente a levedura Candida albicans. Todavia, em seu estudo da atividade antimicrobiana de óleos essenciais em patógenos orais, Bersan (2012) constatou que óleo essencial da espécie inibiu a formação do biofilme de C. albicans em 28,08\%. De acordo com Azzaz et al. (2014), o óleo essencial de priprioca foi inativo frente Aspergillus niger em difusão em disco e CMI, mas foi ativo frente $C$. albicans, com halos de inibição de $10 \mathrm{~mm}$ e CMI 12,5 $\mu \mathrm{g} / \mathrm{ml}$.

Além do óleo essencial de priprioca, foram avaliados tanto extratos de rizomas e tubérculos de priprioca, quanto extratos do resíduo sólido de priprioca. Ngo Bum et al. (2001) e Rakotonirina et al. (2001) caracterizaram o extrato total provenientes da decocção dos rizomas de C. articulatus e identificaram a presença de saponinas, flavonoides, terpenos, taninos e açúcares. Pode-se averiguar que todos os extratos de priprioca foram ativos frente a F. oxysporum e S. sclerotiorum. A ação antifúngica de extratos vegetais frente a fungos fitopatogênicos tem sido avaliada por inúmeros autores (DOMINGUES et al., 2009; FERREIRA et al., 2014; KASPER et al., 2018c; KASPER et al., 2018d)

O extrato etanólico de priprioca inibiu o crescimento fúngico na concentração $250 \mu \mathrm{g} / \mathrm{mL}$, apresentando efeito fungicida na concentração $1000 \mu \mathrm{g} / \mathrm{mL}$ frente a $F$. oxysporum, sendo inativo frente a $S$. sclerotinia e M. phaseolina. Já o extrato etanólico do resíduo sólido de priprioca apresentou efeito inibitório na concentração $125 \mu \mathrm{g} / \mathrm{mL}$ e fungicida na concentração $250 \mu \mathrm{g} / \mathrm{mL}$ para F. oxysporum. Já para S. sclerotinia foi inibitório na concentração $62,5 \mu \mathrm{g} / \mathrm{mL}$ e fungicida na concentração $125 \mu \mathrm{g} / \mathrm{mL}$, sendo inativo frente a $M$. phaseolina. Portanto, o extrato etanólico do resíduo sólido de priprioca apresentou uma atividade antifúngica mais eficiente frente aos microrganismos avaliados.

A atividade antifúngica do extrato hexânico dos rizomas e tubérculos de priprioca não diferiu do extrato hexânico do resíduo sólido de priprioca nas concentrações ativas frente aos fitopatógenos avaliados. Ambos foram inibitórios na concentração $125 \mu \mathrm{g} / \mathrm{mL}$ frente a $F$. oxysporum e $62,5 \mu \mathrm{g} / \mathrm{mL} \mathrm{frente} S$. sclerotiorum e fungicidas na concentração $250 \mu \mathrm{g} / \mathrm{mL}$ para os dois microrganismos. Os dois tratamentos foram inativos frente a Macrophomina phaseolina.

Portanto, os extratos dos resíduos foram tão ativos quanto (extrato hexânico) ou mais ativos (extrato etanólico) que os extratos dos rizomas e tubérculos de priprioca. Sendo assim, a atividade antifúngica do extrato etanólico do resíduo sólido de priprioca revela seu potencial para uso no controle alternativo de fungos fitopatogênicos, já que é obtido de um material de descarte, produzido em grandes quantidades, sem valor agregado e sem utilização de solventes tóxicos. Estes produtos presentam viabilidade econômica para se tornarem matéria-prima de produtos agroecológicos.

\section{CONCLUSÕES}

O óleo essencial de priprioca (Cyperus articulatus L.) foi inativo nas concentrações avaliadas frente 
Fusarium oxysporum, Sclerotinia sclerotirum e Macrophomina phaseolina. O extrato etanólico do resíduo sólido de priprioca se mostrou mais eficiente que o extrato etanólico de priprioca nas concentrações avaliadas frente aos microrganismos teste, sendo fungicida na concentração $250 \mu \mathrm{g} / \mathrm{mL}$ sobre $F$. oxysporum e $125 \mu \mathrm{g} / \mathrm{mL}$ sobre $S$. sclerotiorum.

Tanto o extrato hexânico de rizomas e tubérculos de priprioca quando o extrato hexânico do resíduo sólido de priprioca foram fungicidas frente $F$. oxysporum e S. sclerotinia nas concentrações $250 \mu \mathrm{g} / \mathrm{mL}$. Nesse contexto, constatou-se atividade antifúngica in vitro dos resíduos do processo de obtenção do óleo essencial de priprioca, sendo o extrato etanólico do resíduo sólido de priprioca o mais eficiente e com maior possibilidade de aplicação biotecnológica, já que é obtido de um material de descarte, produzido em grandes quantidades e sem valor agregado.

\section{REFERÊNCIAS}

ABDOLAHI, A.; HASSANI, A.; GHOSTA, Y.; JAVADI, T.; MESHKATALSADAT, M. H.. Essential oils as control agents of postaharvest Alternaria and Penicillium rots on tomato fruits. Journal of Food Safety, v.30, p.341-352, 2010. DOI: http://doi.org/10.1111/j.1745-4565.2009.00211.x/

ABUBAKAR, M. S.; ABDULRAHMAN, E. M.; HARUNA, A. K.. The repellant and antifeedant properties of against Tribolium casteneum Hbst. Phytotherapy Research, v.14, n.4, p.281-283, 2000. DOI: http://doi.org/10.1002/10991573(200006)14:43.3.CO;2-3

AZZAZ, N. A. E.; EL-KHATEEB, A. Y.; FARAG, A. A.. Chemical composition and biological activity of the essential oil of Cyperus articulatus. International Journal of Academic Research, v.6, n.5, 2014. DOI: http://doi.org/10.7813/20754124.2014/6-5/A.37

BERSAN, S. M. F.. Avaliação da atividade antimicrobiana de óleos essenciais frente a patógenos orais. Dissertação (Mestrado em Área de Concentração em Odontologia) Universidade Estadual de Campinas, Piracicaba, 2012.

CELOTO, M. I. B.; PAPA, M. F. S.; SACRAMENTO, L. V. S.; CELOTO, F. J.. Atividade antifúngica de extratos de plantas a Colletotrichum gloeosporioides. Acta Scientiarum Agronomy, Maringá, v.30, n.1, p.1-5, 2008.

DAN, Y.; LIU, H. Y.; GAO, W. W.; CHEN, S. L.. Activities of essential oils from Asarum heterotropoides var. mandshuricum against five phytopathogens. Crop Protection, v.29, p.295-299, 2010. DOI: http://doi.org/10.1016/j.cropro.2009.12.007

DATTA, S.; DHAR, S.; NAYAK, S. S.; DINDA, S. C.. Hepatoprotective activity of Cyperus articulatus Linn.against paracetamol induced hepatotoxicity in rats. Journal of Chemistry Pharmacology Research, v.5, p.314-319, 2013.

DINIZ, S. P. S. S.; COELHO, J. S.; ROSA, G. S.; SPECIAN, V.; OLIVEIRA, R. C.; OLIVEIRA, R. R.. Bioatividade do óleo essencial de Mentha arvensis L. no controle de fungos fitopatógenos. Revista Brasileira de Plantas Medicinais, Botucatu, v.10, n.4, p.9-11, 2008.
DOMINGUES, R. J.; SOUZA, J. D. F.; TÖFOLI, J. G.; MATHEUS, D. R.. Ação 'in vitro' de extratos vegetais sobre Colletotrichum acutatum, Alternaria solani e Sclerotium rolfsii. Arquivos do Instituto Biológico, São Paulo, v.76, n.4, p.643-649, 2009

DUARTE, M. C. T.; FIGUEIRA, G. M.; SARTORATTO, A.; REHDER, V. L. G.; DELARMELINA, C.. Anti-candida activity of Brazilian medicinal plants. Journal of Ethnopharmacology, v.97, p.305-311, 2005

FERREIRA, E. F.; JOSÉ, A. R. S.; BOMFIM, M. P.; PORTO, J. S.; JESUS, J. S.. Uso de extratos vegetais no controle in vitro do Colletotrichum gloeosporioides Penz. coletado em frutos de mamoeiro (Carica papaya L.). Revista Brasileira de Fruticultura, Jaboticabal, v.36, n.2, p.346-352, 2014. DOI: http://doi.org/10.1590/0100-2945-223/13

HILLEN, T.; SCHWAN-ESTRADA, K. R. F.; MESQUINI, R. M.; CRUZ, M. E. S.; STANGARLIN, J. R.; NOZAKI, M.. Atividade antimicrobiana de óleos essenciais no controle de alguns fitopatógenos fúngicos in vitro e no tratamento de sementes. Revista Brasileira de Plantas Medicinais, Botucatu, v.14, n.3, p.439-445, 2012.

LEE, Y.; KIM, J.; SHIN, S.; LEE, S.; PARK, I. I.. Antifungal activity of Myrtaceae essential oils and their components against three phytopathogenic fungi. Flavour Fragrance Journal, v.23, p.23-28, 2008. DOI: http://doi.org/10.1002/ffj.1850

KASPER, A. A. M.; SAN MARTIN, B. S.; SARTORATTO, A.; RUIZ, A. L. T. G.; CASTRO, K. C. F.; BARATTO, L. C.; NUNES, K. M.; BARATA, L. E. S.. Atividade citotóxica do extrato etanólico do resíduo de Cyperus articulatus $L$. frente a linhagens tumorais humanas. In: SIMPÓSIO REGIONAL NORTE DE FARMACOGNOSIA, 2. Anais. Santarém, 2018a.

KASPER, A. A. M.; SOUSA, B. C. M.; LOURIDO, K.; SAN MARTIN, B.; BARATA, L. E. S.; LUSTOSA, D.. Óleo essencial e hidrolato de Cyperus articulatus var. nodosus no controle de Colletotrichum musae, Cadernos de Agroecologia, v.13, n.1, 2018b.

KASPER, A. A. M.; SOUSA, S. F.; SAN MARTIN, B. S.; SOUSA JR. J. J. V.; SARTORATTO, A.; ESCHER, S. K. S.; BARATA, L. E. 
S.. Prospecção de produtos naturais obtidos de priprioca como agentes de controle de fungos fitopatogênicos de importância agrícola. Agroecossistemas, v.10, n.2, p.273286, 2018c. DOI: http://doi.org/10.18542/ragros.v10i2.5200

KASPER, A. A. M.; SOUSA, S. F.; SOUSA JR., J. J. V.; ESCHER, S. K. S.; BARATA, L. E. S.. Comparação da atividade antifúngica do óleo comercial e do extrato etanólico das folhas de nim (Azadirachta indica Juss) frente a fungos fitopatogênicos.

Revista Ibero-americana de Ciências Ambientais, v.9, n.6, 2018d. DOI:

http://doi.org/10.6008/CBPC21796858.2018.006.0007

METUGE, J. A.; BABIAKA, S. B.; MBAH, J. A.; NTIE-KANG, F.; AYIMELE, G. A.; CHO-NGWA, F.. Anti-onchocerca Metabolites from Cyperus articulatus: Isolation, In Vitro Activity and In Silico 'Drug-Likeness', Natural Products Bioprospection, v.4, p.243-249, 2014. DOI: http://doi.org/10.1007/s13659-014-0023-5

NGO BUM, E.; SCHMUTZ, M.; MEYER, C.; RAKATONIRINA, A.; BOPELET, M.; PORTET, C.; JEKER, A.; RAKOTONIRINA, S. V.; OLPE, H. R.; HERRLING, P.. Anticonvulsant properties of the methanolic extract of Cyperus articulatus (Cyperaceae), Journal of Ethnopharmacology, v.76, p.145-150, 2001.

NICOLI, C. M. L.; HOMMA, A. O. K.; MATOS, G. B.; MENEZES, A.. Aproveitamento da biodiversidade amazônica: o caso da priprioca. Belém: Embrapa, 2006.

OOTANI, M. A.; AGUIAR, R. W. S.; MELLO, A. V.; DIDONET, J.; PORTELLA, A. C. F.; NASCIMENTO, I. R.. Toxicidade de óleos essenciais de eucalipto e citronela sobre Sitophilus zeamais Motschulsky (Coleoptera: Curculionidae). Bioscience Journal, Uberlândia, v.27, n.4, p.609-618, 2011.

PANSERA, M. R.; VICENÇO, C. B.; PRANCUTTI, A.; SARTORI, V. C.; RIBEIRO, R. T. S.. Alternative control of the fungus Sclerotinia sclerotiorum (Lib.) de Bary causes agent sclerotinia, with essential oils and plant extracts. Revista
Brasileira de Agroecologia, v.7, n.3, p.126-133, 2012.

RAKOTONIRINA, V. S.; NGO BUM, E.; RAKOTONIRINA, A.; BOPELETA, M.. Sedative properties of the decoction of the rhizome of Cyperus articulatus. Fitoterapia, v.72, n.1, p.2229,2001

RUKUNGA, G. M.; MUREGI, F. W.; OMAR, S. A.; GATHIRWA, J. W.; MUTHAURA, C. N.; PETER, M. G.; HEYDENREICH, M.; MUNGAI, G. M.. Anti-plasmodial activity of the extracts and two sesquiterpenes from Cyperus articulatus, Fitoterapia, p.188-190, 2008. DOl: http://doi.org/10.1016/j.fitote.2007.11.010

SILVA, M. B.; MORANDI, M. A. B.; PAULA JÚNIOR, T. J.; VENZON, M.; FONSECA, M. C. M.. Uso de princípios bioativos de plantas no controle de fitopatógenos e pragas. Informe Agropecuário, Belo Horizonte, v.31, n.255, p.70-77, 2010.

SOUSA, P. J. C.; BRAVIM, L. S.; OLIVEIRA, J. P. T.; ZOGHBI, M G. B.. Efeito do óleo essencial de Cyperus articulatus L. na contratibilidade do músculo liso do íleo isolado de cobaia In: POTIGUARA, R. C. V.; ZOGHBI, M. G. B.. Priprioca um recurso aromático do Pará, Belém: UEPA, 2008.

SOUZA FILHO, A. P. S.; GUILHON, G. M. S. P.; ZOGHBI, M. G. B.; VILHENA, M. S. S.. Atividade alelopática do óleo essencial e extratos dos tubérculos de Cyperus articulatus L. In: POTIGUARA, R. C. V.; ZOGHBI, M. G. B.. Priprioca um recurso aromático do Pará. Belém: UEPA, 2008.

SOYLU, E. M.; KURT, S.; SOYLU, S.. In vitro and in vivo antifungal activities of the essential oils of various plants against tomato grey mould disease agent Botrytis cinerea. International Journal of Food Microbiology, v.143, p.183189, 2010. DOI: http://doi.org/10.1016/j.ijfoodmicro.2010.08.01

TAUBE JÚNIOR, P.; CASTRO, K. C. F.; BARATA, L. E. S. Experimentos de química. Santarém: UFOPA, 2014.

A CBPC - Companhia Brasileira de Produção Científica (CNPJ: 11.221.422/0001-03) detém os direitos materiais desta publicação. Os direitos referem-se à publicação do trabalho em qualquer parte do mundo, incluindo os direitos às renovações, expansões e disseminações da contribuiç̃o, bem como outros direitos subsidiários. Todos os trabalhos publicados eletronicamente poderão posteriormente ser publicados em coletâneas impressas sob coordenação da Sustenere Publishing, da Companhia Brasileira de Produção Científica e seus parceiros autorizados. Os (as) autores (as) preservam os direitos autorais, mas não têm permissão para a publicação da contribuição em outro meio, impresso ou digital, em português ou em tradução. 